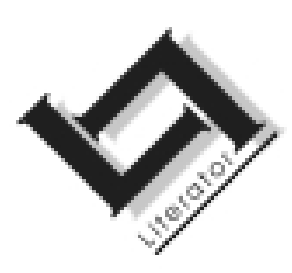

\title{
Register-analysis as a means for eliciting the meaning of literary texts
}

\author{
Chris Jeffery \\ School of Languages \\ University of Port Elizabeth \\ PORT ELIZABETH \\ E-mail: enacdj@upe.ac.za \\ jeffery@eastcape.net
}

\begin{abstract}
Register-analysis as a means for eliciting the meaning of literary texts
\end{abstract}

Intuitive reading of a literary text does not enable one to understand how the text means. For that purpose one needs a suitable semantic theory. This article proposes such a theory, based on the concept of register as meaning-potential. Situation-types have semiotic properties, which set up expectations of the kind of meaning likely in that kind of situation, and those expectations constitute the meaning-potential of the situation, that is the register, which is realised in whatever texts are actually uttered there. So register determines meaning; and register is determined by situationtype, which can be precisely defined by means of categories of (discourse-) situation. Five such categories are put forward. Their application constitutes register-analysis. The process is demonstrated on a literary text; and it is claimed that an intuitive, practical-criticism-type analysis could not be as clear, precise and comprehensive as a register-analysis. And the coherent theory of meaning which supplies the categories also provides a consistent, defined metalanguage to work in. So register-analysis offers a significant advance on intuitive reading.

\section{Linguistic theory can inform intuitive reading}

There is an implicit premiss widely held among literary critics that intuitive linguistic understanding is enough. They see the text as a window opening out onto a meaning which is expected to shine in on them. That comes from the flat-earth theories of meaning imparted by our education-system. A well-founded theory, by contrast, can help critics to seek not simply what a literary text means, but also how it means; and understanding the how is essential to thorough under- 
standing of the what. The present article proposes for this purpose a situation-semantic, or more precisely, situation-semiotic theory due to M.A.K. Halliday, after J.R. Firth and Bronislaw Malinowski.

\subsection{How is meaning created by means of language?}

Two principles are fundamental:

- Language is invariably embedded in some kind of situation, which actually determines its meaning, because the situation's semiotic properties arouse expectations of meaning in the participants.

- Creation of meaning occurs by cooperation between the participants.

\subsubsection{Written language in relation to spoken language}

These principles apply to written language as well, although written texts necessarily constitute the chief component of the situation, and hence the chief source of meaning-determining information. Literary texts especially are packed with a density of information unheard of in colloquial texts. Moreover, because reader and writer cannot cooperate face-to-face like listener and speaker, the cooperation has to be between reader and text. Some of the essential information is brought to the text by its readers, who have to cooperate with it actively to create meaning together, rather than passively absorbing meaning from the text. So the text is more like a mirror than a window, in that it reflects meaning back at you rather than just letting you see the meaning through it.

\section{Situation-types and their semiotic potential}

Situation-semiotic theory is based on the human habit of abstracting types from tokens: intuition detects underlying similarities among distinct phenomena and classifies them accordingly (Lyons, 1977:13-18). Thus the common features of various discourse-situations can be intuitively abstracted to identify a situation-type. 1 Typical features carry conventional meaning, which means that situation-types have semiotic potential, which we have to realise in order to understand the world about us. The semiotic potential of the situation-type is actually fundamental to human communication. The principle can be seen naked in jokes and cartoons, which trade in situation-types, as the following examples show.

1 Originally termed context of situation by J.R. Firth; but since that term tends to be misunderstood and misused for token instead of type, I prefer unambiguous situationtype. See further Wales (2001a). 


\subsection{Examples}

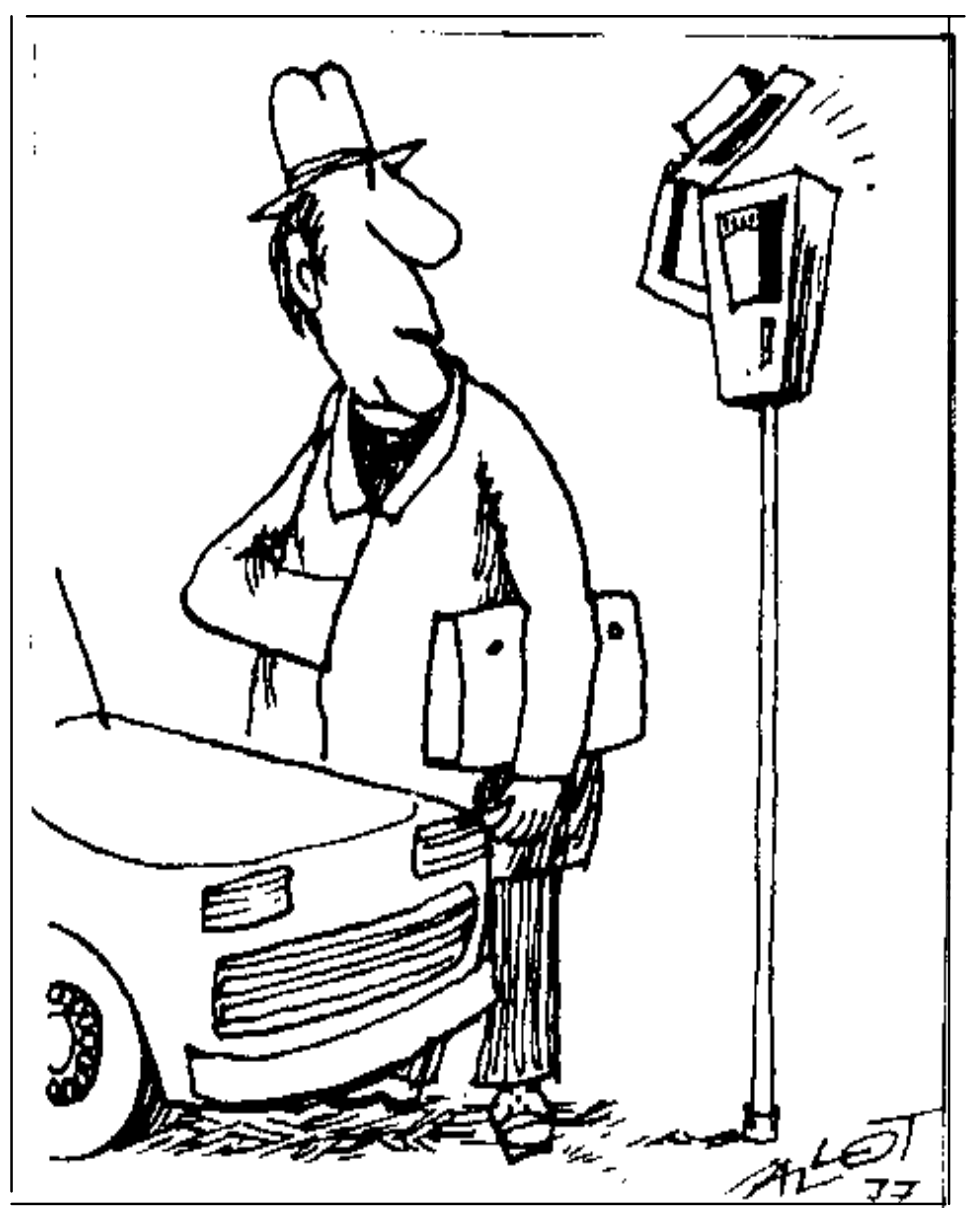

The situation-type in this wordless cartoon is crucially defined by one semiotic feature: the dog-collar on the human figure, which signals "Reverend". Typically, traditionally, as a sign of respect, hats are raised to a Rev. This one is placed in a familiar secular situation-type: beside a motor-car and parking-meter, with hand directed to the typical home of money on men. The single untypical feature, the meter raising its "hat" to him, constitutes the (unfunny) point: a machine paying its respects to the man paying it. My point is that the cartoonist depicts no more than the essentials of the situation-type, and crudely at that, yet we can recognize the signals; we can understand.

The principle remains the same when the situation is created by language rather than by lines on the page:

A lovely young thing entered a doctor's office on her lunch hour and addressed a handsome young man in a white coat: 'l've had a pain in my shoulder for a week. Can you help me?' 
'Lie down on this table,' he said, 'and I'll massage it for you.' After several minutes the beauteous patient exclaimed, 'Doctor, that isn't my shoulder!'

The young man smiled and replied, 'No, and I'm not a doctor, either.'

This joke combines two traditional situation-types: (1) a pretty (and stereotypically gullible) young woman, alone with a handsome (and stereotypically randy) young man, which naturally and conventionally signals "sex"; and (2) a doctor's office, including white coat and table to lie on, which signals "submitting to someone taking liberties with your body". The reader puts (1) and (2) together and infers what kind of liberties were being taken. The joke is feeble (like the cartoon it comes from a ragmag) but useful in showing how typical features convey conventional meaning. Its language is conventional too: expressions like a lovely young thing and the beauteous patient, peculiar to ragmags and Reader's Digest, serve in themselves to create expectations of humorous meaning.

\subsection{Expectations are crucial to meaning}

That is what situation-types do: they create expectations of meaning; that is, they have semiotic potential. This potential determines the meaning of any language used within the situation; or in other words, language means what we expect it to mean in that kind of situation. This crucial point can be illustrated by another cartoon.

\subsubsection{Illustration of the principle}

The situation-type is signalled as suburban-domestic, by lines which we obligingly interpret as typical walls, window and curtains, plus suburbandomestic human types: fat woman in cats-eye specs and beehive hairdo, fat man in vest with rolled-up newspaper. All these typical features are meaningful in our culture. Intruding into this situation is something which, though unlike anything in real life, is recognizable as a typical bug, by its typical bug-features: carapace, stick-like legs, odd mouth, and (very odd) feelers. The striking incongruity, that the bug-type is made threateningly bigger than the human-type, explains the semiotics of their postures: the man is taken aback, and the woman is both pushing him forward and using him as a shield. Their facial expressions are drawn for humour rather than realism (the man has egg-like eyes and no mouth), yet these few lines contrive to denote typical expressions. 


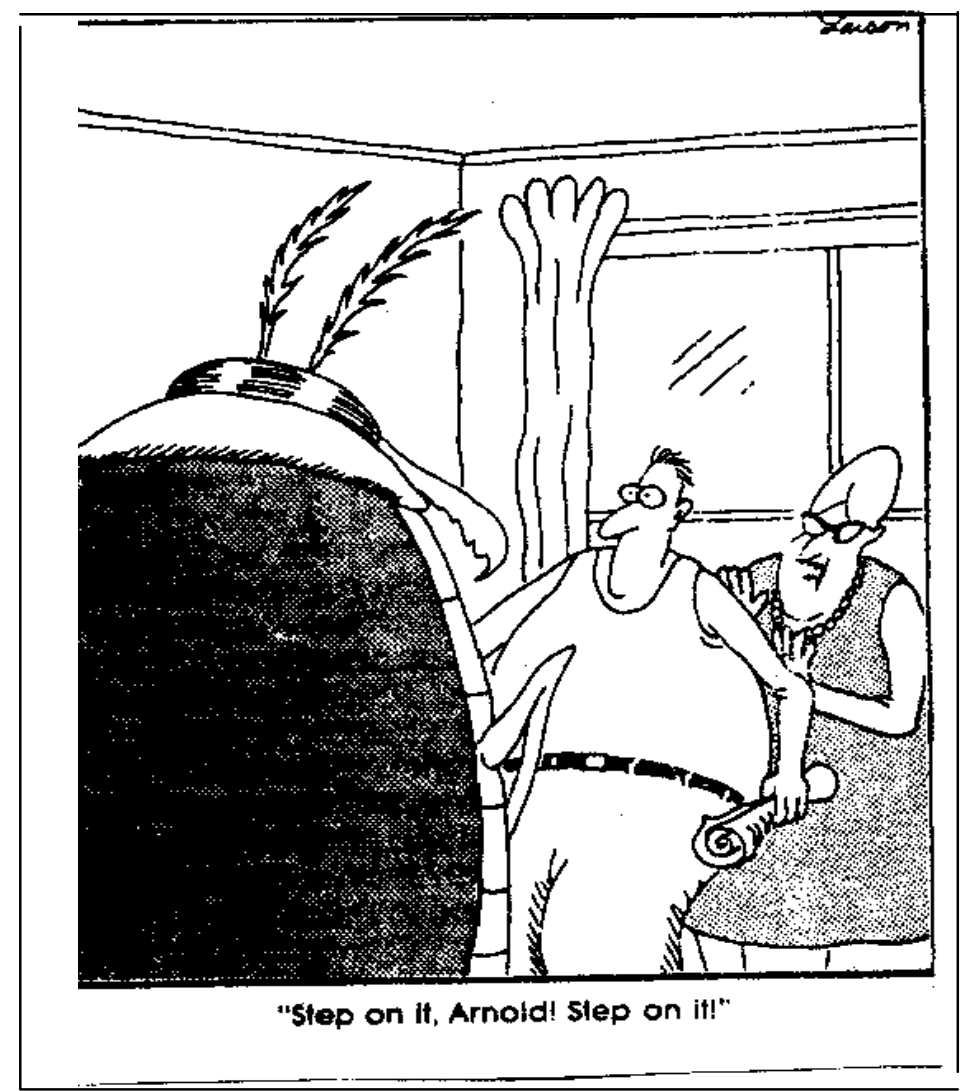

The language attached to this situation is marked as spoken: by inverted commas, repeated imperatives, and direct address to Arnold; and since that must be the name of the man (it seems peculiarly appropriate to the situation-type) and the woman is given an open mouth, it must be her utterance. The meaning of the caption step on it is determined by the situation: bugs intruding into suburban households typically get stepped on. The natural inference from the combination of linguistic and nonlinguistic signals is that she is making a typical demand. The joke is in the one untypical feature: this bug is too big for the man's boots, so her demand is ridiculous, and revealing about her attitude to him. The point here though is the association of meaning with typical features. If they had been given postures signalling imminent flight, then the same caption, that is to say the same text, would have had a quite different meaning, "hurry up". So, our perception of the situation-type determines our selection of the appropriate meaning for the text. The text cannot be autonomous: it is always part of a situation, the type of which we have to abstract in order to discern, or find, meaning in the text. ${ }^{2}$ This particular

2 Meaning depends on context. That is axiomatic. Situation-semiotic theory explains the axiom, and provides a principled and explicit way of relating meaning to context. 
text, step on it, can have either a literal or an idiomatic meaning, and from any particular situation where it occurs we abstract the key typedetermining features which signal which meaning is appropriate. The cartoonist has done the abstracting for us and supplied just these semiotic features and no more; there is no irrelevant information in his picture, whereas in life we must ourselves distinguish relevant information from background noise. 3 But whether in art or in life, the principle remains the same: the information we abstract from a situation determines what meaning we are prepared to find in any accompanying text.

\subsection{Register determines meaning}

Even if the cartoonist had the meaning "hurry up" in mind, it is excluded by the situation-type that he has depicted, for we should not expect that meaning in that kind of situation. So the semiotic features of the situation determine what you can mean. Any and every discourse-situation necessarily has such features: they constitute the significant, typedetermining information which the audience abstracts in order to determine what kind of meaning to expect from any discourse uttered in that situation. In short, the situation-type determines the potential meaning. The term for potential meaning is register, which is realised in texts, and determines their actual meaning. 4 The text is a semantic unit, not necessarily co-terminous with the discrete physical entity called "a text"; Paradise Lost for instance consists of many texts (Halliday, 1978: 135-7). So, the type of situation evokes corresponding expectations of meaning, which constitute the register, which determines the meaning of the texts that realise it, which determines the meaning of the words. Thus

3 Compare the stark abstraction of modern cartoons with the exuberant representationalism of the Victorians. Our forebears had to abstract from Punch almost as much as from life; hence the long-winded captions defining the situation-type. As fashions changed and the noise in the pictures subsided, so less information was needed from the captions, and they could dwindle.

$4 \quad$ The term register as originally propounded in the 1960s denoted a linguistic variety according to use. This concrete, formal concept of register is still useful (e.g. Ghadessy, 1988), but not for understanding how meaning works in language. For that purpose one needs the abstract, semantic concept of register as meaning-potential which Halliday developed during the 1970s (set out in Halliday, 1978). His primary interest was in the exchange of meanings in spoken interaction in face-to-face social situations, which is the normal use of language; and that, especially the socio-politics, has been the focus of various other theoreticians who have been developing refinements of his theory since the 1980s (see further Leckie-Tarry, 1993; Matthiessen, 1993). However, for the special use which is written literature, the semantic concept of register remains the key insight. 
the principle boils down to this: register determines meaning. Meaning trickles down from above rather than bubbling up from below. 5

\section{Defining register: the categories of situation}

Now, how do you tell what the register is? Seeing that in principle register is determined by situation-type, it can be defined by analysing the discourse-situation and asking who is addressing whom about what, and why, and where and when and how, and what the relation is between the participants. These questions are answered, and the answers organised, by means of categories of discourse-situation. Halliday's three categories, field, tenor and mode, need modification: field breaks down usefully into domain and topic; and tenor likewise into functional tenor and personal tenor (this latter distinction is due to Gregory and Carroll, 1978). The category-slots are filled (in any order) by asking various questions:

Mode of discourse: How is the discourse uttered? In spoken language or written? If spoken, is it spontaneous or prepared? If written, and especially if literary, how is the text laid out on the page: as prose, dialogue, or verse? If dialogue, how is spoken language simulated? If verse, what about stanza-form, rhyme-scheme and rhythm? And if printed, what about the typography? It is not always appreciated how much mode contributes to a text's meaning. For example, whereas the prototypical features of recited poetry are rhythm and rhyme, those of written poetry are drawn from lineation and layout (further Chartier, 1989).

Domain of discourse: What is going on around the discourse? What kind of activity is it situated in? How does the discourse relate to the domain; in particular, is the domain also a topic of discourse? The domain of a literary text may comprise on the one hand title, author, date, genre, relationship to other texts in the same genre, and to other works by the same author (Wales, 2001c:220), and on the other hand historical information about the intellectual and socio-political circum-

5 Many generations of linguistic theorists have assumed that sentence-meaning is a compound of word-meaning and grammar; but those alert to polysemy, such as lexicographers, know that this bottom-up approach is fallacious, and that you cannot tell what the words mean without knowing what the sentence means. Consider for instance the meanings of run out in these sentences:

In this bath the hot water runs out faster than the cold.

I was wanting a bath, but the hot water has run out. 
stances. In short, under domain comes all the extratextual information needed in order to make sense of the text.

Topic of discourse: What is the text about? That can often be precisely analysed by means of lexico-semantic sets.

Functional tenor of discourse: What is its purpose? The three categories of function proposed by Halliday are not as useful in practice as the established sextet: referential, expressive, conative, phatic, metalinguistic and poetic (further Halliday, 1978:48-50; Wales, 2001b: 168). The statement can be simply in terms of the categories of function, but there is usually more to say than that.

Personal tenor of discourse: Who is addressing whom? How do they stand in relation to each other? Are the pronouns first-, second- or thirdperson (Wales, 2001d:294)? What are the utterer's attitudes to the topic, and to the audience? Is the presence of an audience explicitly acknowledged? What is the point of view (Wales, 2001e:306)?6

\subsection{Application of the categories}

Application of the categories constitutes register-analysis. The categories can be applied in whatever order serves the main object, which is to bring intuitive inferences out for closer examination, and hence deeper comprehension. Register-analysis is essentially a way of slowing down the inferential process so that we can see what our intuitions are up to. It applies in principle to discourse-situations rather than to discourse in itself. But of course the discourse always constitutes part of the situation; and the main part in the case of literary texts, though never the whole, for every text has an extra-textual situation: no text can constitute its own domain. The purpose of analysing literary texts is to make what Firth liked to call statements of meaning; and what makes register-analysis a powerful tool for the purpose is Halliday's insight that meaning is determined by register. Its methodical interrogation of texts brings to conscious attention features which would otherwise remain subliminal, or entirely unnoticed. Moreover, it provides a well-defined, friendly metalanguage for analysis.

Students of literature tend to resist stylistics, complaining that linguistic theory is arcane, and when applied to literary texts it either tells you

6 It is personal tenor that is (partly) covered by the traditional, ill-defined, lit.crit. category tone, a metaphorical extension of tone of voice, which in spoken language is a linguistic realization of tenor. 
things you do not need to know or merely translates what you already know into a rebarbative metalanguage. Register-analysis, however, is so easy, and satisfying, that in the past few years I have taught the skill within weeks to several hundred initially resistant first-year students of English. Smart seniors learn it in a week. I proceed now to demonstrate on a text apt for the purpose. ${ }^{7}$

\title{
4. Demonstration
}

\section{beware : do not read this poem}

\author{
tonite , thriller was \\ abt an ol woman, so vain she \\ surrounded herself $\mathrm{w} /$ \\ many mirrors
}

5

it got so bad that finally she

locked herself indoors \& her

whole life became the

mirrors

one day the villagers broke

$\begin{array}{cl}\text { into her house , } & \text { but she was too } \\ \text { swift for them : } & \text { she disappeared } \\ \text { into a mirror } & \end{array}$

each tenant who bought the house after that , lost a loved one to the ol woman in the mirror : first a little girl then a young woman then the young woman/s husband

20 the hunger of this poem is legendary it has taken in many victims back off from this poem it has drawn in yr feet back off from this poem it has drawn in yr legs back off from this poem it is a greedy mirror

$7 \quad$ Lyrics are convenient for demonstration in a short space. Register-analysis works just as well on drama and narrative, but there provision has to be made for two orders of situation: that of the actual text, and the fictional situations which it creates. 
30

35

40

45

$$
\begin{aligned}
& \text { you are into this poem . from } \\
& \text { the waist down } \\
& \text { nobody can hear you can they } \\
& \text { this poem has had you up to here } \\
& \text { belch } \\
& \text { this poem aint got no manners } \\
& \text { you cant call out frm this poem } \\
& \text { relax now \& go w/ this poem } \\
& \text { move \& roll on to this poem } \\
& \text { do not resist this poem } \\
& \text { this poem has yr eyes } \\
& \text { this poem has his head } \\
& \text { this poem has his arms } \\
& \text { this poem has his fingers } \\
& \text { this poem has his fingertips } \\
& \text { this poem is the reader \& the } \\
& \text { reader this poem }
\end{aligned}
$$

statistic : the us bureau of missing persons reports that in 1968 over 100,000 people disappeared leaving no solid clues

$$
\text { nor trace only }
$$

a space in the lives of their friends

\subsection{Register-analysis}

\subsubsection{Title}

Mode: no capital letters, eccentric spacing around colon.

Functional tenor: poses as a warning, i.e. conative function, instead of a title, i.e. conventional referential function; but it is referential really, because it is still a title, albeit unconventional, and it does still define the domain and chief topic of the following text, i.e. this poem, since by titling-convention the deictic this points to the following text.

Personal tenor: playful: the poet knows you will not heed the warning, but rather be all the keener to read the poem, out of curiosity; and he knows you know he hopes you will read his poem.

\subsubsection{Text}

Domain: poem, dated 1970, by Ishmael Reed, (cf. Allison et al., 1983: 1370). It belongs to that super-abundant genre of the twentieth century, the lyric. Within this domain there are two palpable changes of register, at lines 19 and 44, signalled most obviously by changes of topic, but also by changes in mode and tenor. There is also a change in tenor at line 38; 
and line 31 is distinct from the surrounding text in both tenor and mode. Thus three main registers and two subsidiary ones show up at once:

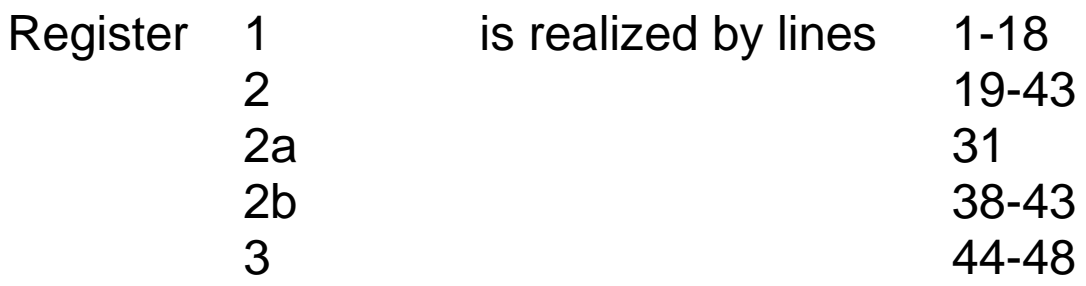

Certain features of mode and tenor remain constant throughout:

Mode: written, laid out as poetry but unrhymed; with several features peculiar to the written mode:

- no capital letters

- eccentric spacing around punctuation-marks (1, 2, 10, 11, 14, 15, $27,28,47,48)$

- eccentric use of full-stop, in the middle of a sentence (27), yet at the end of a sentence only when it occurs in the middle of a line

- eccentric use of / $\mathrm{w} /$ for with $(3,34)$ woman/s for woman's (18)

- no apostrophe aint (32) cant (33)

- graphic abbreviations \& $\quad$ (6, 34, 35, 42) abt (2) yr (22, 24, 37) frm (33)

Personal tenor: the voice remains the same throughout, and is evidently meant to be taken as the poet's. Nevertheless there is occasion to distinguish voice from poet (more on this below). The voice is identified as American by the spelling "tonite" at the beginning and by reference to "the US bureau of missing persons" at the end. For the rest the registers must be taken in turn:

\subsubsection{Register 1 (lines 1-18)}

Topic 1: the plot of a thriller ostensibly seen or heard on the same night as the text was composed.

Functional tenor 1: referential: recounting the plot; this tenor is realised grammatically by the selection of the past tense throughout.

Personal tenor 1: third-person point of view; no overt acknowledgement of either audience/reader or domain; neutral attitude to the topic. Selection of the past tense is consistent with this detachment. Informal spellings "tonite" and "ol", colloquial expression it got so bad, and colloquial syntax throughout, all imply a deliberately simple, informal re- 
telling of the story, as if the voice were actually speaking to an interlocutor. That is incongruent with the specifically written features of mode.

Mode 1: three four-line stanzas with the last line indented, followed by one six-line stanza with the last four lines indented. The lines are all runon up to line 15, and the layout seems arbitrary and unmotivated, as if the text were chopped-up prose, or rather speech. There are in fact some implications of speech in the truncated syntax of lines 1-3 and the generally paratactic syntax; and also in the form "ol" in lines 2 and 15, which (like the "ole" of Uncle Remus) implies colloquial pronunciation of old. These implications reinforce the colloquial impression of the personal tenor. Even so, this text cannot class as written representation of speech, because of its many eccentric, and therefore salient, graphic features without phonic counterparts, including the arbitrary layout. These are all significant features of the mode, without which it would neither be nor feel like the same text. In short, its register and hence its meaning would be different.

\subsubsection{Register 2 (lines 19-43)}

Mode 2: (unlike mode I) a group of six lines, spaced off from a group of eighteen lines with the fourth and seventh indented, and spaced off in turn from a group of two lines. The indentation of the waist down (line 28) is iconic, a visual joke, since it gives the poem a distinct waist. The indentation and isolation of belch (line 31) graphically signals a momentary, word-long, change in register (more on this below). The lineendings coincide with syntactic units up to line 41, but not in lines 42-43. There the apparently wayward ending of line 42 is necessary for the sake of the symmetry of line 43 , where reader and poem balance on the pivot this. The alternative was to attach \& the to line 43 and let this poem and the reader balance over is. This is matter peculiar to the written mode; and I have already pointed out other peculiarly written features; but there are also some markers of spoken language:

- direct address to you (passim)

- imperatives:

back off from $(21,23,25)$

relax now and go $\mathrm{w} /(34)$

move \& roll on to (35)

do not resist (36)

- tag-question:

can they ? (29)

- contractions:

aint (32), cant (33)

- colloquial expressions:

had you up to here (30)

aint got no (32) 
Personal tenor 2: This is complex and playful, and strikingly different to tenor 1 in that you, the reader is addressed directly and drawn into the text (in more than one sense); in fact, the reader's relationship to the domain constitutes the topic; and the voice adopts attitudes to both reader and topic. In dismantling the mechanism it is important to keep certain components separate:

(a) the external situation of the text, from the point of view (i) of the poet writing it;

and (ii) of the reader, reading it line by line.

(b) the internal situation created by this text.

In (b) there is a voice which speaks from the point of view of someone apart from (i) and close to (ii), and regards this poem as already existing, an autonomous, animate object which stands in a predatory relationship to you. This voice addresses you directly, warning of the poem's attitude. By shifting from the intuitively natural (a)(ii) to look instead from (i) we can observe the poet creating a situation (b) in which this poem which he is busy writing already has a legendary past and many victims antecedent to the reader whom he projects as standing at (ii), and who is turned into the next victim by standing there. Furthermore, we can observe him using the poem itself to address, and tease, the reader about the reader:poem relationship.

The playfulness springs partly from the teasingly paradoxical complexity of the mechanism, and partly from the trick of setting the poem:reader relationship in a predator:prey register, which motivates the paradoxical warnings to "back off from this poem", as well as the paradoxical title (more below under topic 2). The trick takes another turn towards the end of the text, once you are so far into it that "you cant call out frm this poem" (line 33): it is too late for warnings now, so you may as well relax and enjoy it (lines 34-36).

The markers of spoken mode (above) also signal an informal, colloquial tenor, which is appropriate to the playfulness. As the text itself puts it, "this poem aint got no manners" (line 32). However, there is a moment of mock-seriousness in the formal warning do not resist, which in tenor matches the beware of the title.

Functional tenor 2: referential, poetic, expressive, and (mock) conative. Written language is used to describe, and evoke, the power of written language to absorb readers by intriguing, puzzling and misleading them. Switching to the present tense signals a different tenor from 1, and is consistent with this close involvement. 
Topic 2: this poem, that is, the domain, in relation to its reader, you. The topic is laid out in terms of a metaphorical identification of this poem with a greedy mirror (line 26), a predator which can be subject to hunger and prey on victims (lines 19-20), like the mirror in the thriller. The text explores the ground of this metaphor (MI), which is itself another metaphor (M2), comparing reading a poem with being swallowed by it, or being taken in by it, in the sense both of being engrossed in it, trying to make out its meaning, and of being tricked by it, because (part of) its meaning is that you can be tricked by poetry. Furthermore, another kind of metaphorical identification of poem and mirror (M3) is implicit, in that you see yourself in it: it addresses you, and allows you to watch yourself being taken in by it. Schematically, then:

Ml: $\quad \mathrm{T}($ enor) this poem $=$ a greedy mirror $\mathrm{V}$ (ehicle) $G$ (round) it swallows people

M2: $T$ people read this poem $=$ it swallows people $\mathrm{V}$ $G$ people get taken in by it

M3: $T$ this poem $=$ a mirror $V$ $G$ you see yourself in it

As I have already hinted, these metaphors create the opportunity for complex potential meaning, or in other words they activate various registers to control the meaning of the same bits of language, so that various actual meanings become possible. In particular:

- " it has taken in many victims" (line 20)

In the "swallowing" register taken in has a literal meaning, in a set with drawn in, greedy and hunger. But this is a metaphorical register to which corresponds another, literal one: being swallowed by a text is a way of saying one is absorbed or engrossed in it (to use two other metaphors!). Furthermore, in colloquial registers of English taken in also has the idiomatic meaning "deceived", and since it fits the topic, and since the personal tenor is markedly colloquial and playful, this meaning is apt: the poem has deceived many readers, while also engrossing them, just as it is busy doing to you.

- " this poem has had you up to here" (line 30)

One potential, colloquial, meaning of had you is again "deceived". So the poem has deceived you up to this point on the page, the point marked by the deictic here. In this register here is pointing at the domain and at itself. 
The whole locution had you up to here has another meaning in colloquial registers, that is "had too much of you". That idiom is based on a metaphor: when you have had food up to the (gestured at) gorge, then you have had more than enough; by a metaphorical transfer, you can have too much of people. The locution is normally only used in this metaphorical way; but in this poem's "swallowing" register the metaphor is reinvested with a literal meaning: the poem has swallowed you up to its gorge, so it utters a belch in the next line (more on that line below). In this register, then, up to here means "up to the throat". But throat also fits into the progressive set feet, legs, waist, eyes, and there are actually two "swallowing" registers: one taking the swallower's point of view on the act, and the other the swallowee's. From that latter perspective it makes sense that the poem has now swallowed you up to your throat. This is really a poem, though, not a predator, and it is not really swallowing you; so there is also a literal meaning in the register defined by the domain: the poem has had you, your attention, so far.

- $\quad$ "this poem has yr eyes" (line 37)

The normal idiomatic meaning of this sentence would be that you are looking at it, that it has your attention, like one of the meanings of had you above. In the "swallowing" register, though, it marks the culmination of the process that started at your feet: you are in it up to your eyes now. The "swallowing" register is carried to fantastic lengths, imagining the details of the swallowing, with the reader in up to the waist, out of hearing of other people, or non-readers, and then the poem belching. This is fantasy rather than metaphor, and having no apparent literal counterpart, it must simply be taken as part of the fun. It could therefore fit just as well under tenor as topic.

\section{Register 2a (line 31)}

Belch is distinct in mode and tenor because it is supposedly uttered by the poem itself. Hitherto the poem has been regarded from outside, but here suddenly it finds its own voice, for one word; yet this word is only a sign that the poem makes an inarticulate sound (perhaps a very special case of heteroglossia). So we arrive at the paradox of a poem that does not actually utter a word.

The next line, "this poem aint got no manners", belongs to the voice again, regarding the poem from outside, and purportedly apologizing for its unmannerly belching. But the language of the apology is itself unmannered, in being sub-standard and unpoetic; so, it implies, the voice aint got no manners neither; but then of course the voice belongs to the poem really, so it is not just the belch that shows that this poem aint got no manners .... 
Register 2b (lines 38-43)

A change in tenor, specifically of point of view, is signalled by the change of pronoun in line 38: from $y r$ to his. That suddenly implies the presence of someone together with whom the erstwhile second-person you-reader is viewed as a third-person someone else who is disappearing into the poem, until he finally becomes identified with it in lines 42-43, which equate reader and poem, like truth and beauty. The ground for this equation lies in Ml: the poem has engrossed the reader to the end; but, by the same token, by reading the poem to the end, you engross it. So the relationships in $\mathrm{Ml}$ invite reversal into another metaphor (M4) in which reading a poem becomes like swallowing it, in that you take it in. Schematically:

\section{M4: $T$ reading this poem $=$ swallowing it $\mathrm{V}$}

$G$ you take it in

So, in order to make sense of these climactic lines you have to tune in to the poem's metaphorical register and invent your own metaphor.

\subsubsection{Register 3 (lines 44-8)}

Topic 3: missing persons in the US in 1968

Mode 3: written language, with no markers of spoken language. Rather attention is drawn to the markers of written language, the graphic conventions, by breaking them. Likewise, the text is marked as poetic mode by the short lines, not right-justified; yet there is no apparent justification for the line-endings: line 44 ends before the Object of the Main Clause, line 45 before the Adverbial of the Subordinate Clause, line 46 before the co-ordinate Object of the Predicator leaving, and line 47 in the middle of the Noun Phrase only a space. The syntax is broken up; and the spacing-conventions of written language are broken too, in the last two lines. The very last line contains a glaring infraction, in the form of a space sticking out beyond the left-hand margin (although statistic: is also outside this margin, in order to signal its deictic function, there is text starting at the margin on the same line, so that anomaly is not so anomalous as this one). The effect is to make a space very prominent, in a word to foreground it, and also to make the mode iconic of the meaning, in that the text graphically leaves a space all around a space.

Functional tenor 3: (mock) referential, realised grammatically by the past tense of disappeared. After the unsettling effect of all the infractions of the rules of written language, and of the difficult meaning in general, it is a relief to arrive at line 44 and feel the firm ground of familiar, immediately comprehensible language in standard form. But even this 
prosaic passage has quicksands: the shift in aspect to present continuous in leaving signals a change in tenor in the last three lines, to poetic and expressive.

Personal tenor 3: impersonal statistic, modulating into personal regret, in which the reader is implicitly invited to share; yet the predominantly playful tenor of the poem leaves doubt about how seriously this regret should be taken. All the more so if one looks for logical cohesion between the registers, principally by topic:

(1) mirror swallows people

(2) poem is mirror, poems swallows readers

(3) a lot of people have vanished.

This sequence invites the not entirely serious conclusion that the missing people have been swallowed by poems. So the text can be read as a playful poem about the power of poetry. It is certainly determined to draw attention to itself as a text. By breaking the graphic conventions of written language it emphasises its status as a graphic object in its own right/ write (or even rite), rather than a mere reflection in space of an object that is supposed to be realised in time, in spoken language. In fact, despite the implications of speech in registers 1 and 2, the poem cannot be adequately realised in the spoken mode. And by thus forcing attention onto the medium, it prevents readers from regarding it simply as a transparent window onto the meaning. It forces us to see it as a mirror instead: we have to stare into the text, as into a mirror, in search of the meaning; we cannot simply look through it. The medium is (part of) the message.

\section{Conclusion}

The message for readers of literary texts is often complicated: there is much information of various kinds coming at them all at once, and it all has a bearing on the meaning - as in the case of this poem. While it would not be impossible to analyse it intuitively in pre-theoretical terms, it would certainly be difficult to arrive at anything as clear, precise and comprehensive as a register-analysis. The categories of situation enable one to sort out all the information and tidy it up, to precisely identify its sources, and to bring out some information which might be missed entirely on a purely intuitive reading. And the coherent theory of meaning which supplies the categories also provides a consistent, defined metalanguage to work in. For students of literature it can pay to kick the habit of intuitive reading. 


\section{Bibliography}

Allison, Alexander W., Barrons, Herbert, Blake, Ceasar R., Carr, Arthur J,. Eastman, Arthur N., English Jnr, Hubert M. (eds.) 1983. The Norton Antholoy of Poetry 3rd ed. New York : Norton.

Chartier, R. 1989. Meaningful forms. Liber, 1:8-9, October.

Ghadessy, M. (ed.) 1988. Registers of Written English. London : Pinter.

Gregory, M. \& Carroll S. 1978. Language and Situation. London : Routledge.

Halliday, M.A.K. 1978. Language as Social Semiotic. London : Arnold.

Leckie-Tarry, H. 1993. The specification of a text: register, genre and language teaching. In: Ghadessy, M. (ed.) Register Analysis: Theory and Practice. London : Pinter. p. 26-42.

Lyons, J. 1977. Semantics. Cambridge : CUP.

Matthiessen, C. 1993. Register in the round: diversity in a unified theory of register analysis. In: Ghadessy, M. (ed.) Register Analysis: Theory and Practice. London : Pinter. p. 221-92.

Reed, Ishmael. 1983. "beware : do not read this poem". In: Allison, Alexander W., Barrons, Herbert, Blake, Ceasar R., Carr, Arthur J,. Eastman, Arthur N., English Jnr, Hubert M. (eds.) The Norton Antholoy of Poetry 3rd ed. New York : Norton. p. 1370.

Wales, Katie. 2001a. Context. In: A Dictionary of Stylistics 2nd ed. London : Longman. p. 81.

Wales, Katie. 2001b. Function. In: A Dictionary of Stylistics 2nd ed. London : Longman. p. 168.

Wales, Katie. 2001c. Intertextuality. In: A Dictionary of Stylistics 2nd ed. London : Longman. p. 220.

Wales, Katie. 2001d. Persona. In: A Dictionary of Stylistics 2nd ed. London : Longman. p. 294.

Wales, Katie. 2001e. Point of view. In: A Dictionary of Stylistics 2 nd ed. London : Longman. p. 306.

\section{Key concepts:}

register

situation semantics

stylistic analysis

\section{Kernbegrippe:}

register

situasionele semantiek

stilistiese ontleding 